\title{
EFFECT OF ORGANIC FERTILIZER FORMS AND DOSES ON THE SEED GERMINATION AND SEEDLING DEVELOPMENT OF RAPESEED (Brassica napus L.)
}

\author{
KAYA, A. R. ${ }^{*}-$ CoşKUN, N. \\ Kahramanmaras Sutcu Imam University, Agricultural Faculty, Department of Field Crops, \\ Kahramanmaraş-Turkey \\ (phone: +90-0-344-3002164; fax: +90-0344-3002-002) \\ ${ }^{*}$ Corresponding author \\ e-mail: alirahmikaya@ksu.edu.tr \\ (Received 12 ${ }^{\text {th }}$ May 2020; accepted $13^{\text {th }}$ Aug 2020)
}

\begin{abstract}
In this study, the effects of organic fertilizer forms and doses on the seed germination and seedling growth of rapeseed were investigated. A study was carried out according to the Completely Randomized Experimental Design with three replications. Under liquid seaweed, germination index, radicle fresh weight, and radicle, plumule and seedling dry weights were found to be highest, while germination percentage, radicle length, plumule length, seedling length and germinated seed number proved to be the lowest. In liquid vermicompost; radicle length, plumule length, seedling length, radicle fresh weight, radicle dry weight and seedling vigor index were the highest. The liquid organic fertilizer with plant-derived amino acids proved to be the highest germination percentage value and the lowest radicle length, radicle fresh weigth, plumule fresh weight, seedling fresh weight, and radicle, plumule and seedling dry weight and seedling vigor index. The liquid vermicompost had an effect on increasing the seedling length by encouraging radicle and plumule length of the rapeseed, while liquid seaweed had negative effects on radicle and plumule length. It has been shown an effect to increase seedling fresh weight by promoting seedling growth. It was determined that the liquid organic fertilizer with plant-derived amino acids form encouraged the germination percentage of rapeseed. All tested fertilizers had an inhibitory effect on germination, on the other hand, the fertilizers promoted the seedling growth.
\end{abstract}

Keywords: liquid seaweed, liquid vermicompost, organic fertilizer, rapeseed, seedling vigor index

\section{Introduction}

Rapeseed, which can be grown sustainably in two different periods, summer and winter, contains $38-50 \%$ fat and $16-24 \%$ protein. Rapeseed is an important oil plant. In Turkey; it is also called rapiska, rapitsa and canola (Algan, 1990). Rapeseed oil with a neutral $\mathrm{pH}$ level is used as canned and frying oil in the food industry, and its nutritional properties and high boiling point ofconstitute some of its most important features (Tosun and Özkal, 2000). Rapeseed is also used as a raw material in the production of biodiesel with approximately $40 \%$ crude oil it contains, and it provides an important contribution to animal nutrition with the remaining $60 \%$ pulp.

Rapeseed is very useful in the beekeeping industry as well as in the food industry. It is a good source of food for bees that ensure dust intake from yellow flowers of rapeseed in March-April, when the flowers are scarce (Şeker, 2015). Rapeseed production with these benefits and uses; It ranks third in the world with 75001457 tons of oilseed plants such as soybean, cotton, peanut, sunflower, safflower and sesame. According to 2018 data, the world rapeseed cultivation is 37579575 ha and the yield is $1995.8 \mathrm{~kg} \mathrm{ha}^{-1}$ (FAOSTAT, 2020).

According to the 2019 data in Turkey in rapeseed cultivation; 52515 ha cultivation, $3430.0 \mathrm{~kg} \mathrm{ha}^{-1}$ yield and 180000 tons' production, and $61.87 \%$ of 111358 tons were 
produced in the West Marmara Region. The highest production is in Tekirdağ province with a ratio of $33.61 \%$ with 60497 tons (TURKSTAT, 2020).

Today, urbanization and industrialization have increased, fertile agricultural lands are decreasing, so it is necessary to obtain more products from the unit area in order to meet the nutritional needs of the increasing population. Here, fertilization has become mandatory to regain nutrients lost from the soil.

According to Adolf Mayer, "fertilization is the process of feeding the plant nutrients to the soil in order to increase the yield power of the culture soils and increase the quality and quantity of the product to be obtained. The substances used for this purpose are called "fertilizer" (Kacar, 2013).

Here, in order to increase the production quality of rapeseed, it should not disrupt the structure of the soil, crop rotation should be applied, organic fertilizer should be used, and biological control method which does not spoil the structure of the soil should be used. Human beings have to reestablish the natural balance lost in this ecological system as a result of wrong practices. Organic farming is a production system that is friendly to nature and the environment. It ensures that the soil has a sustainable yield, increases plant resistance, promotes biological methods without using chemicals in plant protection, and aims to increase the quality of the product in production.

Organic fertilization, on the other hand, improves soil yield, sustainability and water-holding capacity, improves soil and accelerates microbial activities (Yüksek et al., 2019). Another important feature of organic fertilizers is that they are a good soil conditioner (Aygün and Acar, 2004). The use of organic extracts (fertilization, plant growth regulators, etc.) has proven effective in improving seed germination and early seedling growth in abiotic stress conditions (Sharma et al., 2014). Seaweed and vermicompost extracts from these organic extracts have found use in seed applications (Demir et al., 2006; Ma et al., 2017; Masondo et al., 2018).

One of these extracts is vermicompost, also known as vermicompost, which is among the soil improvers and nutrients used in organic agriculture. Vermicompost is the process of composting organic waste by worms. The worm fertilizer produced as a result of the vermicompost process consists of completely organic materials, contains plant nutrients and some plant growth hormones. Therefore, it makes it possible to buy more products from the unit area.

Solid worm manure is a product obtained by composting. Liquid worm manure is called processed state of composted manure. So, it is obtained from solid worm manure. Liquid worm fertilizer is an odorless, brown and slightly alkaline (7-9 pH) organic liquid. In liquid worm manure; it contains humates, fulvic acids, amino acids, vitamins, natural hormones, micro and macro elements $(\mathrm{N}, \mathrm{P}, \mathrm{K}, \mathrm{O}, \mathrm{Ca}, \mathrm{Mg}, \mathrm{S})$ found in solid earthworm fertilizer in a concentrated form of soil microorganism spores (Benitez et al., 2000).

Liquid worm fertilizer accelerates the growth and growth of the plant, has no harm on humans, animals and soil, stimulates the root formation of plants and allows them to form strong roots Protects the soil and the plant from harmful pests and pathogens that may occur in the soil. By providing natural immunity to plants, it eliminates the occurrence of disease in parts such as leaves and stems, accelerates flowering in pot plants, and provides faster crop formation in greenhouse plants. When applied to the leaves of the plant, it gives vitality to the leaf and supports the formation of more photosynthesis, accelerates the metabolism of the plant, prolongs the waiting period in storage of plants or nutrients, delays the decay of the plant, it is a form of liquid fertilizer which is highly recommended for use in agriculture. Liquid worm manure is dark colored, high viscosity and has a long 
shelf life. It is obtained using various technologies, and and the organic substance is rich in humic and fulvic acid amounts (Y1ldırım, 2019). The second of these extracts, seaweed (maxicrop), was obtained from the seaweed called Ascophyllum nodosum on the Norwegian coast. There is auxin (indole and derivatives) and cytokinin (zeatin, kinetin, adenine, purine and adenosine) as growth regulators in seaweed. Seaweeds contain macro $\left(0.75 \% \mathrm{~N}, 1 \% \mathrm{P}_{2} \mathrm{O}_{5}, 16 \% \mathrm{~K}_{2} \mathrm{O}, 0.20 \% \mathrm{Mg}, 2.90 \% \mathrm{~S}\right)$ and micro (30 ppm B, $290 \mathrm{ppm} \mathrm{Fe}$, $12 \mathrm{ppm} \mathrm{Cu}, 56 \mathrm{ppm} \mathrm{Zn}$,) elements. It is also an excellent source of bioactive compounds by growth promoting substances such as seaweeds, essential fatty acids, vitamins, amino acids, minerals, organic osmolites (e.g. betainees) and gibberellins (Spinelli et al., 2010).

Seaweed extracts and suspensions from brown algae are studied in the cultivation of garden plants. Marmarin (seaweed extract) is a biostimulant that increases the production and quality of agricultural products and is widely used in vegetable production (Amanpoor et al., 2011). Seaweed extracts have beneficial effects on plants such as early seed germination, increasing plant performance and yield, high resistance to biotic and abiotic stress and extending the shelf life of seeds. Seaweed extract as an organic biostimulant is one of the applications quickly accepted in horticultural crops due to its beneficial effects. In experimental studies, it has been observed that seedling growth is stimulated by using seaweed extracts (Demir et al., 2006). However, since the high concentration of seaweed can cause loss of yield in the plant, it is necessary to pay attention to the method and duration of application. (Spinelli et al., 2010).

The third of these extracts is a liquid organic fertilizer with plant-derived amino acids. It has a high content of organic matter and contains nitrogen. Therefore, it enables plants to grow faster, bushy and healthier. The liquid organic fertilizer with plant-derived amino acids provide a smooth flowering, promote the number and quality of fruit, shorten the harvest time, provide early crop, increase the resistance of plants against adverse soil and climate factors. Therefore, it is an important liquid organic fertilizer.

In the study, liquid worm manure, liquid seaweed manure, and liquid organic fertilizer forms with plant-derived amino acids were used. It is aimed to determine the encouraging or preventing effects of organic fertilizer forms and doses on the rapeseed (Brassica napus L.) seed germination and seedling growth. and liquid organic fertilizer with plant-derived amino acids

\section{Material and Methods}

This study was carried out in Kahramanmaraş Sütçü İmam University Faculty of Agriculture, Department of Field Crops, Industrial Plants Laboratory in the climate cabinet in January 2020 in Turkey. In the experiment, healthy and homogenous rapeseed (ES Hydromel variety) seeds were used as material.

The research aimed to investigate the effects of different organic fertilizer forms and doses on the germination and seedling growth of rapeseed using a completely randomized experimental design with three replications, in order to find the most optimal combination.

Three fertilizer forms (OF1: liquid seaweed, OF2: liquid organic fertilizer with plant-derived amino acids and OF3: liquid vermicompost) and six doses (FD1: control, FD2: 1000 ppm L ${ }^{-1}$, FD3: 2000 ppm L ${ }^{-1}$ FD4: $4000 \mathrm{~L}^{-1}$, FD5: 8000 ppm L ${ }^{-1}$, FD6: $16000 \mathrm{ppm} \mathrm{L}^{-1}$ ) were applied. Solutions were prepared by diluting fertilizer doses with tap water. Seeds were placed in petri dishes. After leaving two layers of drying paper on the bottom of each petri dish $(90 \mathrm{~mm})$, seven $\mathrm{ml}$ of fertilizer doses prepared were added 
to the drying papers in the petri dish. Surface sterilization was performed in the seeds for five minutes in the solution created with $5 \% \mathrm{NaOCl}$ (sodium hypochlorite) (Y1lmaz, 2015). 25 healthy and similar sized seeds were planted. It is coated with parafilm (PM-992) to prevent water loss in petri dishes. It was allowed to germinate for 14 days in an incubator with a temperature of $25 \pm 2{ }^{\circ} \mathrm{C}$. On the 15 th day, the seeds were measured for germination and seedling growth (Figure 1). The germinated seeds were counted and divided by the total number of seeds and then multiplied by 100 to get the germination rate. Radicle and plumule lengths were measured with calipers. Seedling length was determined by sum of the radicle lenght and plumule lenght. Radicle and plumule were weighed as fresh, and radicle fresh weight and plumule fresh weight were summed and seedling fresh weight was obtained. The samples were then kept for 24 hours at $78^{\circ} \mathrm{C}$ in the etuv and the dry weight of the radicle and dry weight of the plumula were weighed and the sum of the seedling dry weights were found. As a result of the multiplication of seedling length and germination rate, seedling vigor index was found.

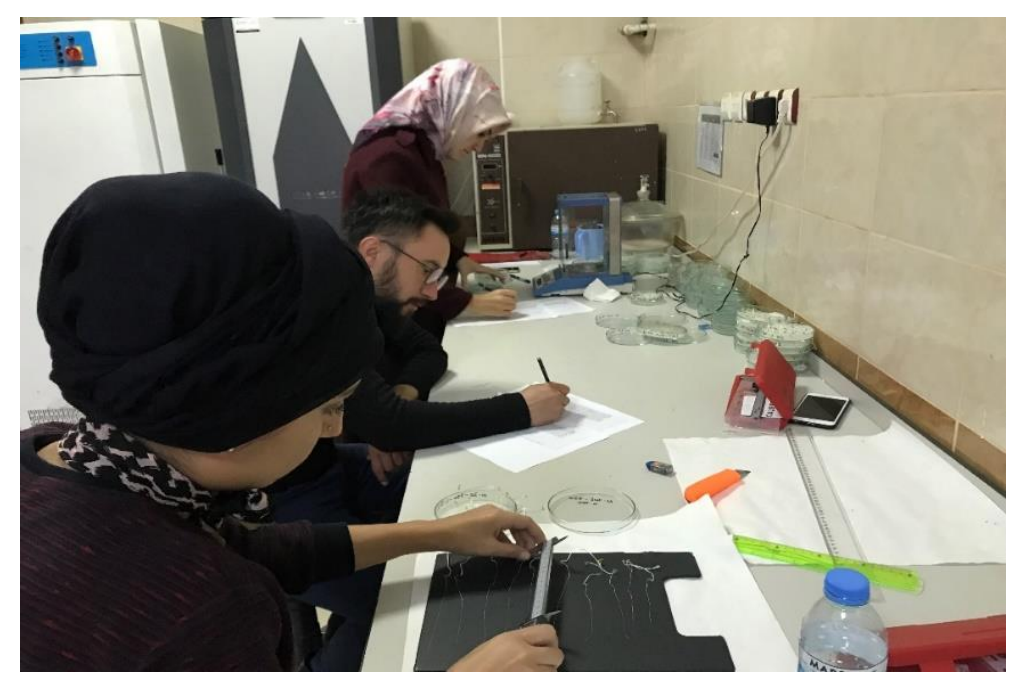

Figure 1. In the laboratory with climate cabinet, an oven, precision scales, etc., on the 15th day after placing; while seeds are measured for germination and seedling development

\section{Statistical analysis of data}

All data obtained from the study were processed by SAS (v. 9.0, 2002) statistical package. The data were analyzed using analysis of variance (ANOVA) according to the Completely Randomized Experimental Design. Averages were compared by Least Significant Difference multiple comparison test (Stell and Toor, 1980).

\section{Results and Discussion}

Averages of the effects of organic fertilizer forms and doses on the seed germination and seedling growth of rapeseed are given in Table 1 and Table 2. According to these tables, fertilizer doses has significantly affected all attributes of germination and seedling. The differences between fertilizer doses, organic fertilezer forms, and their interaction averages were found to be statistically significant for all observed attributes. However, since there was no germination in the OF1-FD6 application, the comparison of the fertilizer $\mathrm{x}$ dose interactions averages was performed over 17 values. 
Table 1. The means of organic fertilizer forms and doses for GP, GI, RL, PL, SL, RFW properties of Brassica napus L. seeds, and LSD groups

\begin{tabular}{|c|c|c|c|c|c|c|c|c|c|c|c|c|c|}
\hline Fertilizer & 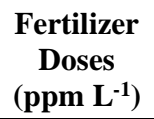 & $\begin{array}{l}\text { GP } \\
(\%)\end{array}$ & $* ; * *$ & GI & $* ; * *$ & $\begin{array}{c}\mathbf{R L} \\
(\mathbf{m m})\end{array}$ & $* ; * *$ & $\begin{array}{c}\text { PL } \\
(\mathbf{m m})\end{array}$ & $* ; * *$ & $\begin{array}{c}\text { SL } \\
(\mathbf{m m})\end{array}$ & $* ; * *$ & $\begin{array}{r}\text { RFW } \\
(\mathbf{m g})\end{array}$ & $* ; * *$ \\
\hline \multirow{7}{*}{ OF1 } & FD1 & 95.11 & $\mathrm{a}$ & 8.22 & $\mathrm{a}$ & 112.72 & $\mathrm{a}$ & 43.21 & $\mathrm{~b}$ & 155.93 & $\mathrm{a}$ & 7.74 & $\mathrm{~d}$ \\
\hline & FD2 & 90.67 & $\mathrm{a}$ & 6.19 & $\mathrm{~b}$ & 95.88 & $\mathrm{c}$ & 45.72 & $a b$ & 141.60 & $\mathrm{~b}$ & 4.87 & $\mathrm{f}$ \\
\hline & FD3 & 34.67 & $\mathrm{f}$ & 1.76 & $\mathrm{~d}$ & 3.01 & $\mathrm{jk}$ & 7.22 & $\mathrm{~h}$ & 10.23 & $\mathrm{~h}$ & 7.60 & $\mathrm{~d}$ \\
\hline & FD4 & 17.33 & $\mathrm{j}$ & 1.03 & $\mathrm{~h}$ & 3.37 & $\mathrm{jk}$ & 6.24 & $\mathrm{~h}$ & 9.61 & $\mathrm{~h}$ & 7.88 & d \\
\hline & FD5 & 25.33 & hi & 1.37 & fg & 5.72 & $\mathrm{ij}$ & 14.30 & $\mathrm{f}$ & 20.03 & $\mathrm{~g}$ & 17.40 & $\mathrm{a}$ \\
\hline & FD6 & - & & - & & - & & - & & - & & - & \\
\hline & Mean & 43.85 & $\mathbf{C}$ & 3.09 & $\mathbf{A}$ & 36.78 & B & 19.45 & $\mathrm{C}$ & 56.23 & $\mathrm{C}$ & 7.58 & $\mathbf{A}$ \\
\hline \multirow{7}{*}{ OF2 } & FD1 & 95.11 & $\mathrm{a}$ & 8.22 & $\mathrm{a}$ & 112.72 & $\mathrm{a}$ & 43.21 & $\mathrm{~b}$ & 155.93 & $\mathrm{a}$ & 7.74 & $\mathrm{~d}$ \\
\hline & FD2 & 57.33 & $\mathrm{c}$ & 3.55 & $\mathrm{c}$ & 36.64 & fg & 27.19 & $\mathrm{~cd}$ & 63.83 & d & 8.60 & $\mathrm{c}$ \\
\hline & FD3 & 34.67 & $\mathrm{f}$ & 1.36 & fg & 10.88 & $\mathrm{i}$ & 11.84 & $\mathrm{~g}$ & 22.72 & $\mathrm{~g}$ & 9.17 & $\mathrm{c}$ \\
\hline & FD4 & 45.33 & d & 1.78 & d & 4.17 & $\mathrm{jk}$ & 7.68 & $\mathrm{~h}$ & 11.85 & $\mathrm{~h}$ & 3.02 & $\mathrm{i}$ \\
\hline & FD5 & 29.33 & g & 0.70 & $\mathrm{i}$ & 41.56 & $\mathrm{f}$ & 43.81 & $\mathrm{~b}$ & 85.37 & $\mathrm{c}$ & 1.90 & $\mathrm{j}$ \\
\hline & FD6 & 58.67 & $\mathrm{c}$ & 1.66 & de & 19.38 & $\mathrm{~h}$ & 18.50 & $\mathrm{e}$ & 37.88 & $\mathrm{f}$ & 1.03 & $\mathrm{k}$ \\
\hline & Mean & 53.41 & $\mathbf{A}$ & 2.88 & B & 37.56 & B & 25.37 & B & 62.93 & B & 5.24 & B \\
\hline \multirow{7}{*}{ OF3 } & FD1 & 95.11 & $\mathrm{a}$ & 8.22 & $\mathrm{a}$ & 112.72 & $\mathrm{a}$ & 43.21 & $\mathrm{~b}$ & 155.93 & $\mathrm{a}$ & 7.74 & $\mathrm{~d}$ \\
\hline & FD2 & 62.67 & $\mathrm{~b}$ & 3.83 & $\mathrm{c}$ & 106.87 & $a b$ & 47.55 & $\mathrm{a}$ & 154.41 & $\mathrm{a}$ & 6.70 & $\mathrm{e}$ \\
\hline & FD3 & 26.67 & gh & 1.25 & gh & 47.83 & e & 7.09 & $\mathrm{~h}$ & 54.92 & e & 15.50 & b \\
\hline & FD4 & 41.33 & $\mathrm{e}$ & 1.09 & $\mathrm{~h}$ & 102.50 & $\mathrm{bc}$ & 43.64 & $\mathrm{~b}$ & 146.13 & b & 6.90 & $\mathrm{e}$ \\
\hline & FD5 & 22.67 & $\mathrm{i}$ & 0.70 & $\mathrm{i}$ & 58.28 & $\mathrm{~d}$ & 28.15 & $\mathrm{c}$ & 86.42 & $\mathrm{c}$ & 4.10 & g \\
\hline & FD6 & 26.67 & gh & 1.50 & ef & 34.82 & $\mathrm{~g}$ & 25.71 & $\mathrm{~d}$ & 60.53 & $\mathrm{~d}$ & 3.50 & $\mathrm{~h}$ \\
\hline & Mean & \begin{tabular}{|l|l|}
45.85 \\
\end{tabular} & B & 2.76 & $\mathbf{C}$ & \begin{tabular}{|l|l|}
77.17 \\
\end{tabular} & $\mathbf{A}$ & 32.56 & $\mathbf{A}$ & 109.72 & $\mathbf{A}$ & 7.41 & $\mathbf{A}$ \\
\hline Mean & & \begin{tabular}{|l|l|}
47.70 \\
\end{tabular} & & 2.91 & & 50.50 & & 25.79 & & 76.30 & & 6.74 & \\
\hline \multicolumn{2}{|c|}{ LSD $(0.05)$ for OF } & $\begin{array}{l}1.53 \\
2.16\end{array}$ & & $\begin{array}{l}0.10 \\
0.15\end{array}$ & & $\begin{array}{l}2.57 \\
3.64\end{array}$ & & $\begin{array}{l}0.84 \\
1.19\end{array}$ & & $\begin{array}{l}2.16 \\
3.05\end{array}$ & & $\begin{array}{l}0.22 \\
0.31\end{array}$ & \\
\hline \multirow{2}{*}{\multicolumn{2}{|c|}{$\begin{array}{c}\text { LSD (0.05) for OF x FD } \\
\text { CV }(\%)\end{array}$}} & 6.49 & & 0.44 & & 10.92 & & 0.58 & & 9.15 & & 0.93 & \\
\hline & & 4.74 & & 5.23 & & 7.52 & & 4.83 & & 4.17 & & 4.80 & \\
\hline
\end{tabular}

GP: Germination Percentage, GI: Germination Index, RL: Radicle Length, PL: Plumule Length, SL: Seedling Length, RFW: Radicle Fresh Weight, Fertilizer Doses: FD1: control, FD2: 1000 ppm L ${ }^{-1}$, FD3: 2000 ppm L-1, FD4: $4000 \mathrm{~L}^{-1}$, FD5: 8000 ppm L-1, FD6: 16000 ppm L ${ }^{-1}$ OF1: Liquid Seaweed, OF2: Liquid Organic Fertilizer with Plant-Derived Amino Acids, OF3: Liquid Worm Fertilizer

*: The mean in the same column, expressed in lowercase and indicated with different letters, is statistically different from each other within the $\mathrm{P} \leq 0.05$ error limits according to LSD test

**: The mean in the same column, expressed in capital and indicated with different letters, is statistically different from each other within the $\mathrm{P} \leq 0.05$ error limits according to LSD test

\section{Germination Percentage (\%)}

It seems that OF2 is more encouraging in terms of germination percentage. The highest germination percentage among fertilizer forms was observed in OF2 with 53.41\%, while the lowest germination percentage was obtained from OF1 fertilizer with $43.85 \%$. In fertilizer $\mathrm{x}$ dose interaction, the highest germination percentage was observed in OF3-FD1, OF2-FD1, OF1-FD1 and OF1-FD2 (95.11, 95.11, 95.11, and 90.67\%, respectively). When the control doses were ignored, the highest germination percentage was seen in OF1-FD2 with $90.67 \%$. Therefore, in addition to seedling growth, liquid seaweed has been determined as a promoter in seed germination. However, the trend of germination percentage at increasing doses in liquid seaweed showed a downward decline. The lowest germination percentage was seen in OF1-FD4 with $17.33 \%$ (Table 1 and Figure 2). 
Table 2. The means of organic fertilizer forms and doses on PFW, SFW, RDW, PDW, SDW, FVI, GSN properties of Brassica napus L. seeds, and LSD groups

\begin{tabular}{|c|c|c|c|c|c|c|c|c|c|c|c|c|c|c|c|}
\hline ertilizer & \begin{tabular}{|c|} 
Fertilizer \\
Doses (ppm \\
$\left.\mathbf{L}^{-1}\right)$ \\
\end{tabular} & $\begin{array}{l}\text { PFW } \\
\text { (mg) }\end{array}$ & $* ; * *$ & $\begin{array}{l}\text { SFW } \\
(\mathbf{m g})\end{array}$ & $* ; * *$ & $\begin{array}{l}\text { RDW } \\
\text { (mg) }\end{array}$ & $* ; * *$ & $\begin{array}{c}\text { PDW } \\
(\mathbf{m g})\end{array}$ & $* ; * *$ & $\begin{array}{l}\text { SDW } \\
(\mathrm{mg})\end{array}$ & $* ; * *$ & FVI & $* ; * *$ & $\begin{array}{c}\text { GSN } \\
\text { (number) }\end{array}$ & $* ; * *$ \\
\hline \multirow{7}{*}{ OF1 } & FD1 & 47.228 & $\mathrm{c}$ & 54.972 & $\mathrm{~d}$ & 0.852 & $\mathrm{~d}$ & 5.195 & $\mathrm{c}$ & 6.047 & $\mathrm{~d}$ & 14848.52 & $a$ & 23.78 & $\mathrm{a}$ \\
\hline & FD2 & 41.733 & d & 46.600 & $\mathrm{e}$ & 0.535 & $\mathrm{f}$ & 4.591 & d & 5.126 & $\mathrm{e}$ & 12832.02 & $b$ & 22.67 & $\mathrm{a}$ \\
\hline & FD3 & 71.633 & a & 79.233 & $\mathrm{a}$ & 0.836 & d & 7.880 & $\mathrm{a}$ & 8.716 & $\mathrm{a}$ & 354.74 & $\mathrm{ijk}$ & 8.67 & $\mathrm{f}$ \\
\hline & FD4 & 59.500 & $\mathrm{~b}$ & 67.383 & $\mathrm{~b}$ & 0.867 & $\mathrm{~d}$ & 6.545 & $\mathrm{~b}$ & 7.412 & $\mathrm{~b}$ & 166.84 & $\mathrm{jk}$ & 4.33 & $\mathrm{j}$ \\
\hline & FD5 & 42.900 & $d$ & 60.300 & $\mathrm{c}$ & 1.914 & $\mathrm{a}$ & 4.719 & d & 6.633 & $\mathrm{c}$ & 507.31 & $\mathrm{ij}$ & 6.33 & hi \\
\hline & FD6 & - & & - & & - & & - & & - & & - & & - & \\
\hline & Mean & 43.832 & A & 51.415 & $\mathbf{A}$ & 0.834 & $\mathbf{A}$ & 4.822 & $\mathbf{A}$ & 5.656 & $\mathbf{A}$ & 4784.90 & B & 10.96 & $\mathrm{C}$ \\
\hline \multirow{7}{*}{ OF2 } & FD1 & 47.228 & $\mathrm{c}$ & 54.972 & $\mathrm{~d}$ & 0.852 & $\mathrm{~d}$ & 5.195 & $\mathrm{c}$ & 6.047 & $\mathrm{~d}$ & 14848.52 & $a$ & 23.78 & $\mathrm{a}$ \\
\hline & FD2 & 43.367 & $\mathrm{~cd}$ & 51.967 & d & 0.946 & $\mathrm{c}$ & 4.770 & $\mathrm{~cd}$ & 5.716 & $\mathrm{~d}$ & 3658.81 & e & 14.33 & $\mathrm{c}$ \\
\hline & FD3 & 25.300 & $\mathrm{e}$ & 34.473 & $\mathrm{f}$ & 1.009 & $\mathrm{c}$ & 2.783 & $\mathrm{e}$ & 3.792 & $\mathrm{f}$ & 787.89 & $\mathrm{i}$ & 8.67 & $\mathrm{f}$ \\
\hline & FD4 & 18.692 & fg & 21.708 & $\mathrm{~h}$ & 0.332 & $\mathrm{i}$ & 2.056 & $\mathrm{fg}$ & 2.388 & $\mathrm{~h}$ & 537.63 & $\mathrm{ij}$ & 11.33 & d \\
\hline & FD5 & 18.467 & $\mathrm{fg}$ & 20.367 & $\mathrm{~h}$ & 0.209 & $\mathrm{j}$ & 2.031 & fg & 2.240 & $\mathrm{~h}$ & 2504.41 & $\mathrm{f}$ & 7.33 & $\mathrm{~g}$ \\
\hline & FD6 & 15.100 & $\mathrm{~h}$ & 16.133 & $\mathrm{i}$ & 0.114 & $\mathrm{k}$ & 1.661 & $\mathrm{~h}$ & 1.775 & $\mathrm{i}$ & 2222.36 & fg & 14.67 & $\mathrm{c}$ \\
\hline & Mean & 28.025 & $\mathrm{C}$ & 33.270 & $\mathrm{C}$ & 0.577 & B & 3.083 & $\mathrm{C}$ & 3.660 & $\mathbf{C}$ & 4093.27 & $\mathrm{C}$ & 13.35 & $\mathbf{A}$ \\
\hline \multirow{7}{*}{ OF3 } & FD1 & 47.228 & $\mathrm{c}$ & 54.972 & $\mathrm{~d}$ & 0.852 & $\mathrm{~d}$ & 5.195 & $\mathrm{c}$ & 6.047 & $\mathrm{~d}$ & 14848.52 & $a$ & 23.78 & $\mathrm{a}$ \\
\hline & FD2 & 47.067 & $\mathrm{c}$ & 53.767 & d & 0.737 & $\mathrm{e}$ & 5.177 & $\mathrm{c}$ & 5.914 & d & 9671.49 & $\mathrm{c}$ & 15.67 & $\mathrm{~b}$ \\
\hline & FD3 & 44.500 & $\mathrm{~cd}$ & 60.000 & $\mathrm{c}$ & 1.705 & $\mathrm{~b}$ & 4.895 & $\mathrm{~cd}$ & 6.600 & $\mathrm{c}$ & 1460.83 & $\mathrm{~h}$ & 6.67 & gh \\
\hline & FD4 & 42.033 & $\mathrm{~d}$ & 48.933 & $\mathrm{e}$ & 0.759 & e & 4.624 & d & 5.383 & $\mathrm{e}$ & 6043.51 & $\mathrm{~d}$ & 10.33 & $\mathrm{e}$ \\
\hline & FD5 & 19.877 & $\mathrm{f}$ & 23.977 & $\mathrm{~g}$ & 0.451 & $\mathrm{~g}$ & 2.186 & $\mathrm{f}$ & 2.637 & g & 1963.63 & $\mathrm{gh}$ & 5.67 & $\mathrm{i}$ \\
\hline & FD6 & 17.333 & $\mathrm{~g}$ & 20.833 & $\mathrm{~h}$ & 0.385 & $\mathrm{~h}$ & 1.907 & $\mathrm{~g}$ & 2.292 & $\mathrm{~h}$ & 1612.86 & $\mathrm{~h}$ & 6.67 & gh \\
\hline & Mean & 36.340 & B & 43.747 & B & 0.815 & $\mathbf{A}$ & 3.997 & B & 4.812 & B & \begin{tabular}{|l|}
5933.47 \\
\end{tabular} & $\mathbf{A}$ & 11.46 & B \\
\hline Mean & & \begin{tabular}{|l|}
36.07 \\
\end{tabular} & & 42.81 & & \begin{tabular}{|l|}
0.74 \\
\end{tabular} & & 3.97 & & 4.71 & & 4937.21 & & 11.93 & \\
\hline \multicolumn{2}{|c|}{ LSD $(0.05)$ for $\mathrm{OF}$} & 1.106 & & 1.10 & & \begin{tabular}{|l|l|}
0.02 \\
\end{tabular} & & 0.12 & & 0.12 & & 264.58 & & 0.38 & \\
\hline $\mathbf{L S D}(0$ & .05 ) for FD & 1.564 & & 1.55 & & 0.03 & & 0.17 & & 0.17 & & 374.17 & & 0.54 & \\
\hline \multicolumn{2}{|c|}{ LSD $(0.05)$ for $\mathrm{OF} \times \mathrm{FD}$} & \begin{tabular}{|l|}
4.693 \\
4.528 \\
\end{tabular} & & $\begin{array}{l}4.66 \\
3.79\end{array}$ & & \begin{tabular}{|l|}
0.10 \\
4.76
\end{tabular} & & $\begin{array}{l}0.52 \\
4.53\end{array}$ & & $\begin{array}{l}0.51 \\
3.80\end{array}$ & & \begin{tabular}{|c|}
1122.51 \\
7.91
\end{tabular} & & $\begin{array}{l}1.62 \\
4.74\end{array}$ & \\
\hline
\end{tabular}

PFW: Plumule Fresh Weight, SFW: Seedling Fresh Weight, RDW: Radicle Dry Weight, PDW: Plumule Dry Weight, SDW: Seedling Dry Weight, SVI: Seedling Vigor Index, GSN: Germinated Seed Number, Fertilizer Doses: FD1: control, FD2: 1000 ppm L-1, FD3: 2000 ppm L-1, FD4: $4000 \mathrm{~L}^{-1}$, FD5: 8000 ppm $\mathrm{L}^{-1}$, FD6: $16000 \mathrm{ppm} \mathrm{L}^{-1} \mathrm{OF} 1$ : Liquid Seaweed, OF2: Liquid Organic Fertilizer with Plant-Derived Amino Acids, OF3: Liquid Worm Fertilizer

*: The mean in the same column, expressed in lowercase and indicated with different letters, is statistically different from each other within the $\mathrm{P} \leq 0.05$ error limits according to LSD test **: The mean in the same column, expressed in capital and indicated with different letters, is statistically different from each other within the $\mathrm{P} \leq 0.05$ error limits according to LSD test

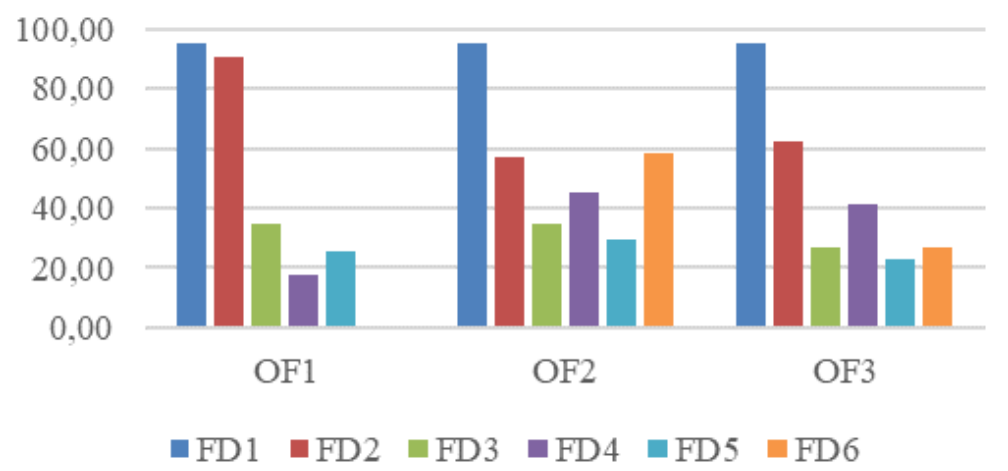

Figure 2. The interaction of organic fertilizers' germination percentage 
Demirkaya (2010), in his study on the effects of seaweed (Ascophyllum nodosum) extract applications on the viability and strength of pepper and onion seeds; found that OC (Osmotic Conditioning: Pre-Germination) applications with seaweed extract increase the germination rate of onion and pepper seeds according to the control application. The results are consistent with the highest finding of germination percentage in OF1-FD2 in fertilizer $x$ dose interaction.

Demirkaya (2012), in his another study on the effects of seaweed (Ascophyllum nodosum) extract applications on the viability and strength of tomato seeds; found that OK applications with seaweed extract increased the germination rates of the seeds of three tomato varieties compared to the control application. The results are similar to the highest finding of germination percentage in OF1-FD2 in fertilizer $\mathrm{x}$ dose interaction.

Y1ldırım and Güvenç (2005), in their study on the effect of seaweed extract practices on seed germination in leeks; They found that with the application of seaweed extract to leek seeds, the rate and speed of seed germination increased significantly compared to the control. The results are consistent with the highest finding of germination percentage in OF1-FD2 in fertilizer $x$ dose interaction.

Matysiak et al. (2011), in their study on the effect of seaweed extracts and the mixture of humic and fulvic acid on germination and growth of corn; reported that extracts from seaweeds (Kelpak SL and AlgaminoPlant) stimulate corn seed germination more than humic and fulvic acids (HumiPlant) and increase by 16-19\%. The results are consistent with the highest finding of germination percentage in OF1-FD2.

\section{Germination Index}

It is seen that OF1 is higher in terms of Germination index average. The highest germination index among the fertilizer forms was seen in OF1 with 3.09, while the lowest germination index was obtained from the OF3 fertilizer form with 2.76. In fertilizer $x$ dose interaction, the highest germination index was found in 8.22 with OF3-FD1, OF2-FD1 and OF1-FD1. The lowest germination index was observed in OF2-FD5 and OF3-FD5 with 0.70 (Table 1 and Figure 3).

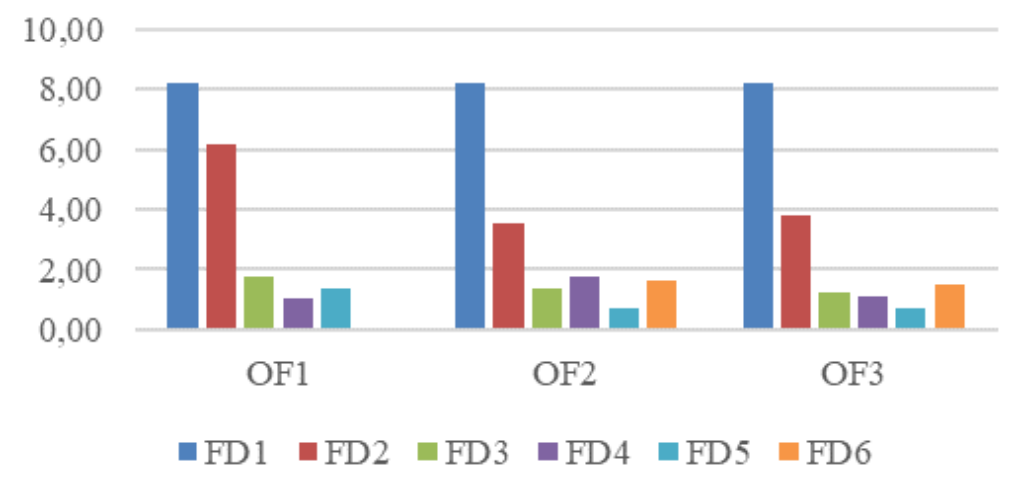

Figure 3. The interaction of organic fertilizers' germination index

Yıldırım and Güvenç (2005), in their study on the effect of seaweed extract applications on seed germination in leeks; they found that with the application of seaweed extract to leek seeds, the rate and speed of seed germination increased significantly compared to control. The results are in line with the highest germination index finding in OF1. 


\section{Radicle Length (mm)}

It is seen that OF3 is more encouraging in terms of the average of the radicle length. Among the fertilizer forms, the highest radicle length was observed in OF3 with $77.17 \mathrm{~mm}$, while the lowest radicle length was obtained from OF2 (37.56 mm) and OF1 $(36.78 \mathrm{~mm})$ fertilizer forms. In fertilizer $\mathrm{x}$ dose interaction, the highest radicle length was $112.72 \mathrm{~mm}$ with OF3-FD1, OF2-FD1 and OF1-FD1. The lowest radicle length was observed in OF1-FD3, OF1-FD4 and OF2-FD4 (3.01, 3.37, and $4.17 \mathrm{~mm}$, respectively) (Table 1 and Figure 4).

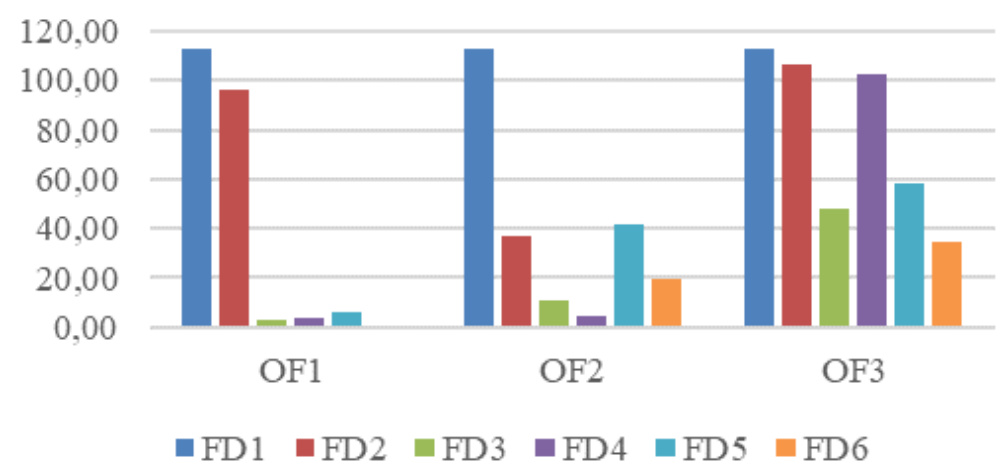

Figure 4. The interaction of organic fertilizers' radicle length

\section{Plumule Length (mm)}

When plumule length averages are examined, it is seen that OF3 has a more positive effect on plumule length. Among the fertilizer forms, the highest plumule length was $32.56 \mathrm{~mm}$ with OF3 fertilizer form. The lowest plumule length was obtained from OF1 fertilizer form with $19.45 \mathrm{~mm}$. In fertilizer $\mathrm{x}$ dose interaction, the highest plumule length was observed in OF3-FD2 with $47.55 \mathrm{~mm}$. The lowest plumule length was observed in OF1-FD4, OF3-FD3, OF1-FD3 and OF2-FD4 (6.24, 7.09, 7.22, and $7.68 \mathrm{~mm}$, respectively) (Table 1 and Figure 5).

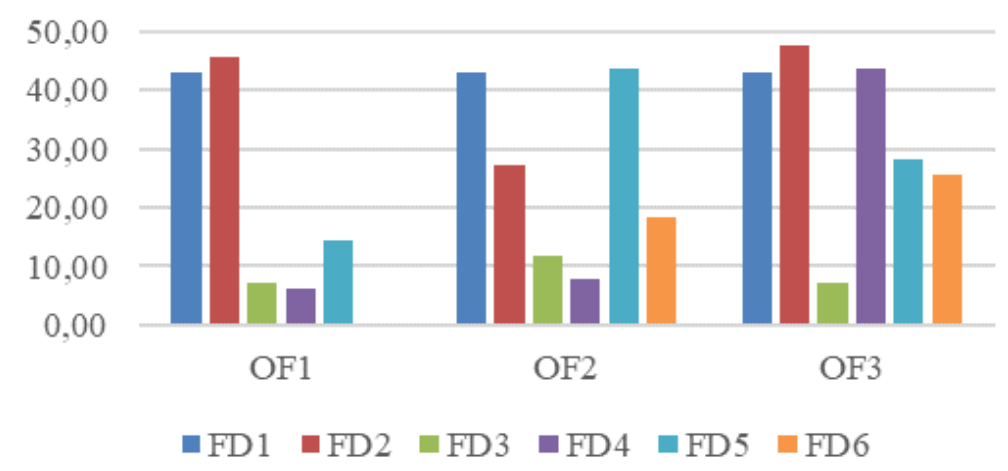

Figure 5. The interaction of organic fertilizers' plumule length

\section{Seedling Length ( $\mathrm{mm})$}

It is seen that OF3 is more encouraging in terms of Seedling length average. While the highest seedling length was seen in OF3 with $109.72 \mathrm{~mm}$ in fertilizer forms, the lowest 
seedling length was obtained from OF1 fertilizer form with $56.23 \mathrm{~mm}$. In fertilizer x dose interaction, the highest seedling length was observed in OF3-FD1, OF2-FD1, OF1-FD1 and OF3-FD2 (155.93, 155.93, 155.93, and $154.41 \mathrm{~mm}$, respectively). The lowest seedling length was observed in OF1-FD4 OF1-FD3 and OF2-FD4 (9.61, 10.23, and $11.85 \mathrm{~mm}$, respectively) (Table 1 and Figure 6).

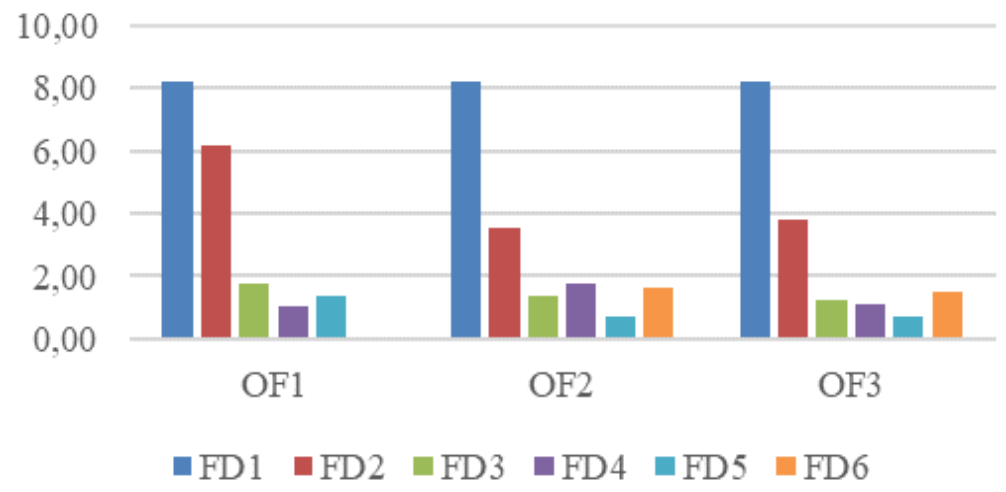

Figure 6. The interaction of organic fertilizers' seedling length

Alam et al. (2007), reported that vermicompost and N P K S fertilizers increased the effect of red amaranth on the growth, yield and yield components of red amaranth, and vermicompost application increased the control of vermicompost compared to control applications. The findings support the highest seedling length in OF3.

\section{Radicle Fresh Weight (mg)}

It is seen that $\mathrm{OF} 1$ and $\mathrm{OF} 3$ are higher in terms of radicle fresh weight average. While the highest radicle fresh weights were observed with OF1 $(7.58 \mathrm{mg})$ and OF3 $(7.41 \mathrm{mg})$ among fertilizer forms, the lowest radicle fresh weight was obtained from OF2 fertilizer form with $5.24 \mathrm{mg}$. In fertilizer $\mathrm{x}$ dose interaction, the highest radicle fresh weight was observed in OF1-FD5 with $17.40 \mathrm{mg}$. The lowest radicle fresh weight was observed in OF2-FD6 with $1.03 \mathrm{mg}$ (Table 1 and Figure 7).

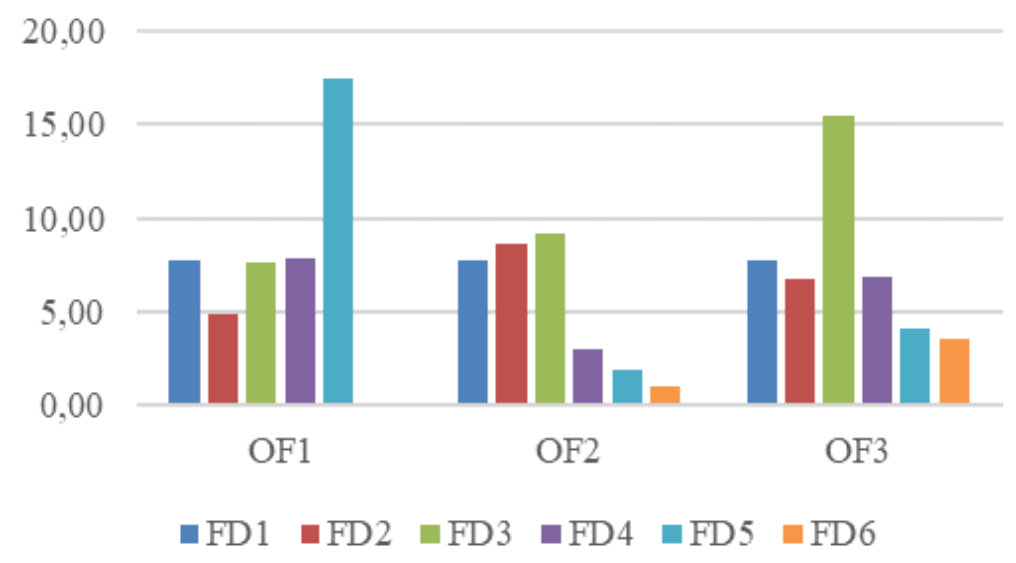

Figure 7. The interaction of organic fertilizers' radicle fresh weigth 


\section{Plumule Fresh Weight (mg)}

It is seen that OF1 is higher in terms of plumule fresh weight average. While the highest plumule fresh weight was observed in OF1 with $43.832 \mathrm{mg}$ among fertilizer forms, the lowest plumule fresh weight was obtained from OF2 fertilizer form with $28.025 \mathrm{mg}$. In fertilizer $\mathrm{x}$ dose interaction, the highest plumule fresh weight was observed in OF1-FD3 with $71.633 \mathrm{mg}$. The lowest plumule fresh weight was seen in OF2-FD6 with $15.100 \mathrm{mg}$ (Table 2 and Figure 8).

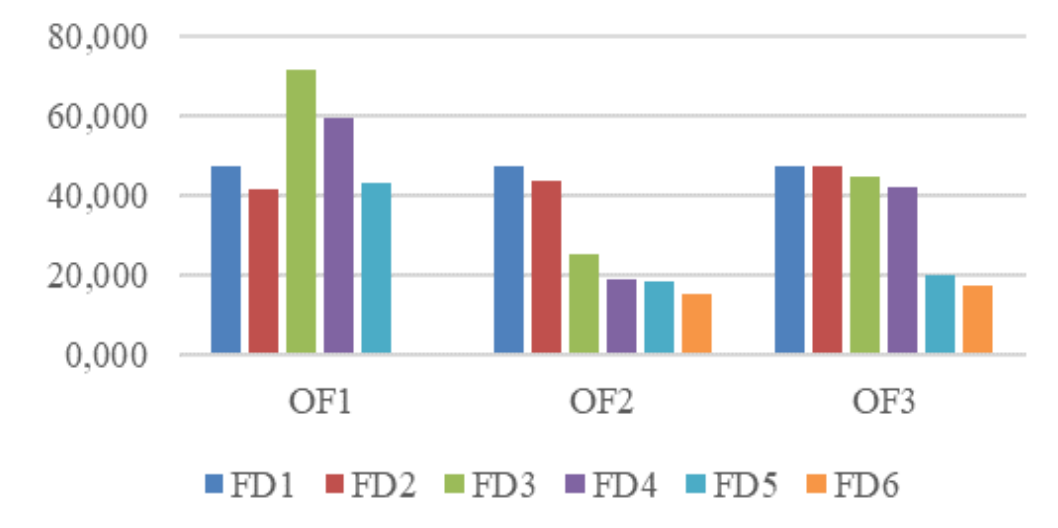

Figure 8. The interaction of organic fertilizers' plumule fresh weigth

Matysiak et al. (2011), in their study on the effect of seaweed extracts and the mixture of humic and fulvic acid on germination and growth of corn; reported that extracts from seaweeds (Kelpak SL and AlgaminoPlant) increased corn plumule fresh weight. The results are consistent with the highest plumule wet weight finding in OF1-FD3.

\section{Seedling Fresh Weight (mg)}

It is seen that OF1 is higher in terms of seedling fresh weight average. While the highest seedling fresh weight was seen in OF1 with $51.415 \mathrm{mg}$ among fertilizer forms, the lowest seedling fresh weight was obtained from OF2 fertilizer form with $33.270 \mathrm{mg}$. In fertilizer $x$ dose interaction, the highest seedling fresh weight was seen in OF1-FD3 with $79.233 \mathrm{mg}$. The lowest seedling fresh weight was observed in OF2-FD6 with $16.133 \mathrm{mg}$ (Table 2 and Figure 9).

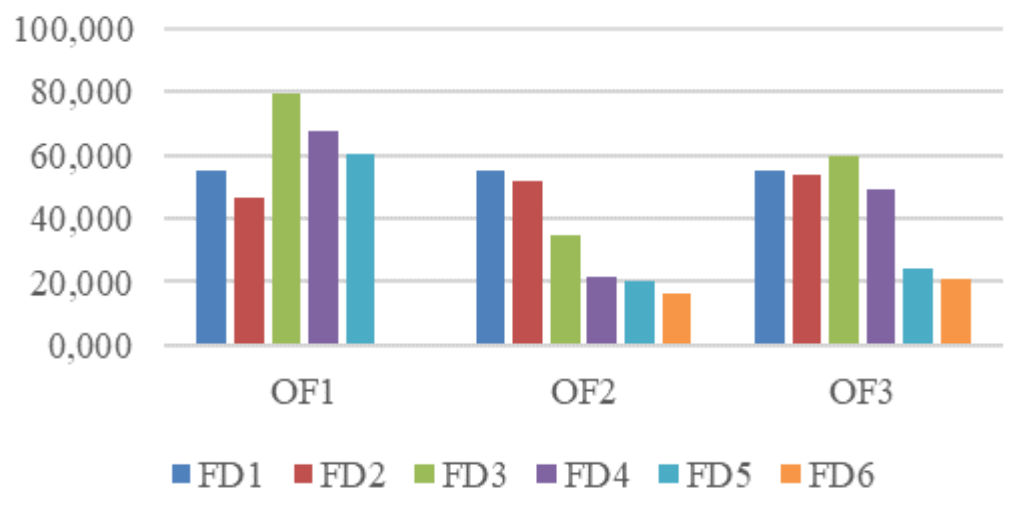

Figure 9. The interaction of organic fertilizers' seedling fresh weigth 


\section{Radicle Dry Weight (mg)}

It is seen that OF1 and OF3 are higher in terms of the average of radicle dry weight. Among the fertilizer forms, the highest radicle dry weights were seen in OF1 $(0.834 \mathrm{mg})$ and OF3 $(0.815 \mathrm{mg})$, while the lowest radicle dry weight was obtained from OF2 fertilizer form with $0.577 \mathrm{mg}$. In fertilizer $\mathrm{x}$ dose interaction, the highest radicle dry weight was found in OF1-FD5 with $1.914 \mathrm{mg}$. The lowest radicle dry weight was found in OF2-FD6 with $0.114 \mathrm{mg}$ (Table 2 and Figure 10).

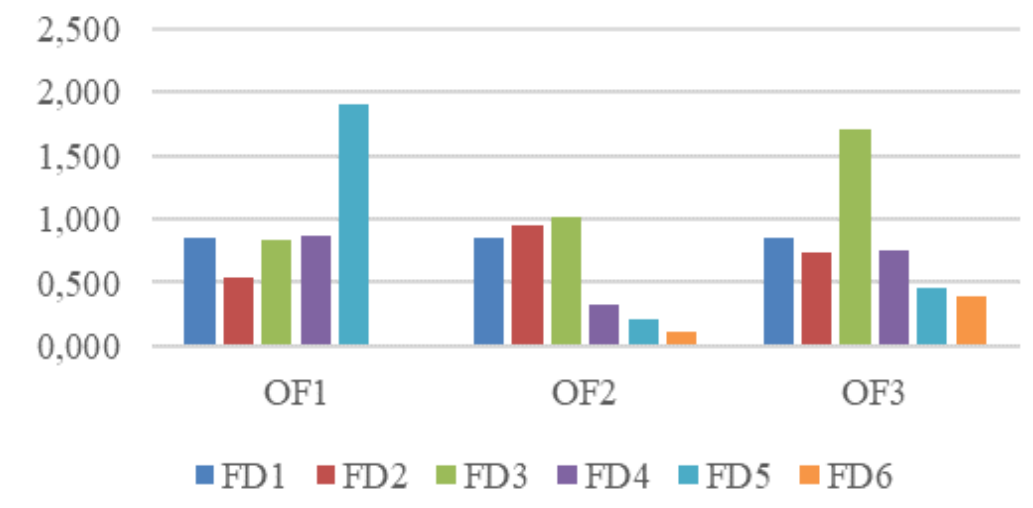

Figure 10. The interaction of organic fertilizers' radicle dry weigth

\section{Plumule Dry Weight (mg)}

OF1 is higher in terms of plumule dry weight average. While the highest plumule dry weight was observed in OF1 with $4.822 \mathrm{mg}$, the lowest plumule dry weight was obtained from OF2 fertilizer form with $3.083 \mathrm{mg}$. In fertilizer $\mathrm{x}$ dose interaction, the highest plumule dry weight was observed in OF1-FD3 with $7.880 \mathrm{mg}$. The lowest plumule dry weight was seen in OF2-FD6 with $1.661 \mathrm{mg}$ (Table 2 and Figure 11).

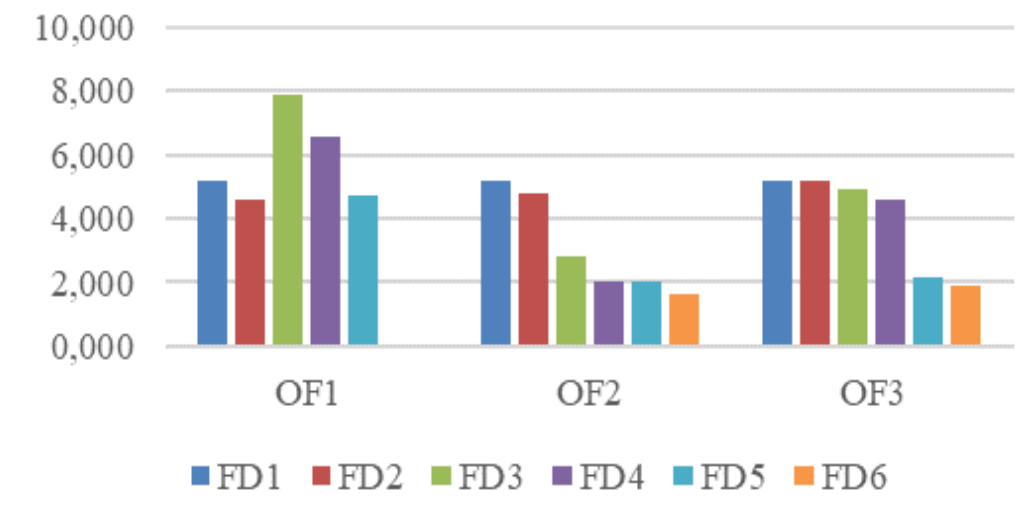

Figure 11. The interaction of organic fertilizers' plumule dry weigth

\section{Seedling Dry Weight (mg)}

As seen in Table 2, OF1 is higher in terms of seedling dry weight average. While the highest seedling dry weight was found in OF1 with $5.656 \mathrm{mg}$ among fertilizer forms, the lowest seedling dry weight was obtained from OF2 fertilizer with $3.660 \mathrm{mg}$. In fertilizer 
$\mathrm{x}$ dose interaction, the highest seedling dry weight was found in OF1-FD3 with $8.716 \mathrm{mg}$. The lowest seedling dry weight was observed in OF2-FD6 with $1.775 \mathrm{mg}$ (Table 2 and Figure 12).

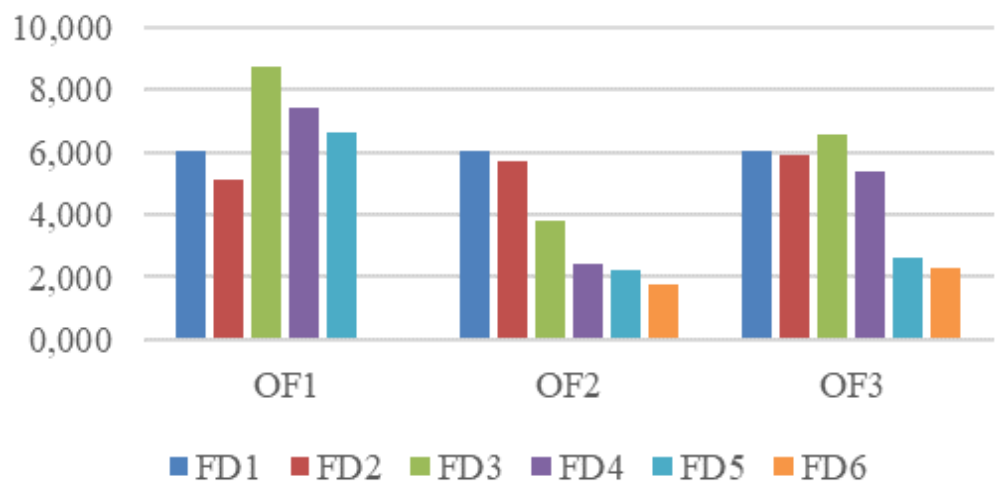

Figure 12. The interaction of organic fertilizers' seedling dry weigth

\section{Seedling Vigor Index}

It is seen that OF3 is higher in terms of seedling vigor index average. Among the fertilizer forms, the highest seedling vigor index was seen in OF3 with 5933.47, while the lowest seedling vigor index was obtained from OF2 fertilizer form with 4093.27. In fertilizer $x$ dose interaction, the highest seedling vigor index 14848.52 was seen in OF3-FD1, OF2-FD1 and OF1-FD1. The lowest seedling vigor index was seen in OF1-FD4 with 166.84 (Table 2 and Figure 13).

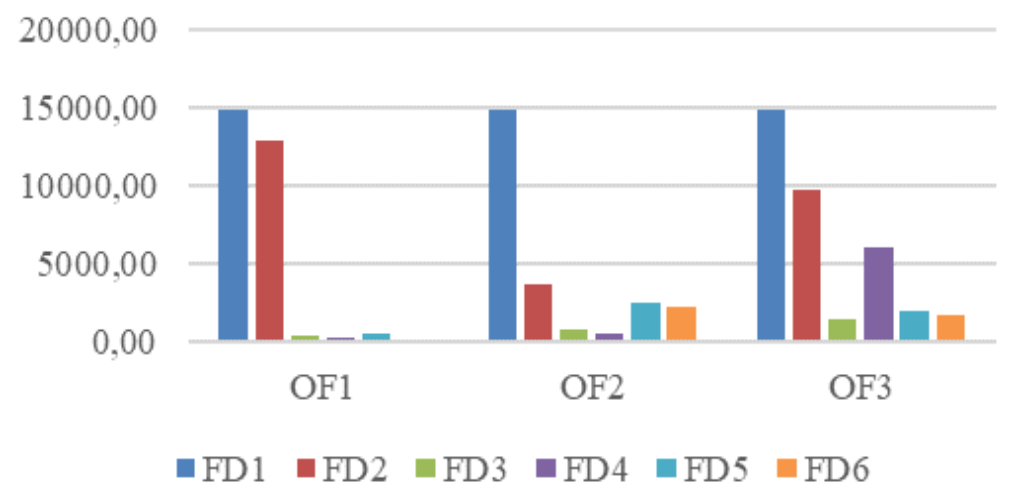

Figure 13. The interaction of organic fertilizers' seedling vigor index

\section{Germinated Seed Number (number)}

It is seen that OF2 is higher in terms of average of germinated seed number. The highest germinated seed number among the fertilizer forms was seen in OF2 with 13.35, while the lowest germinated seed number was obtained from the OF1 fertilizer form with 10.96. In fertilizer $x$ dose interaction, the highest germinated seed number was observed in OF3-FD1, OF2-FD1, OF1-FD1 and OF1-FD2 (23.78, 23.78, 23.78, and 22.67, respectively). The lowest germinated seed number was found in OF1-FD4 with 4.33 (Table 2 and Figure 14). 


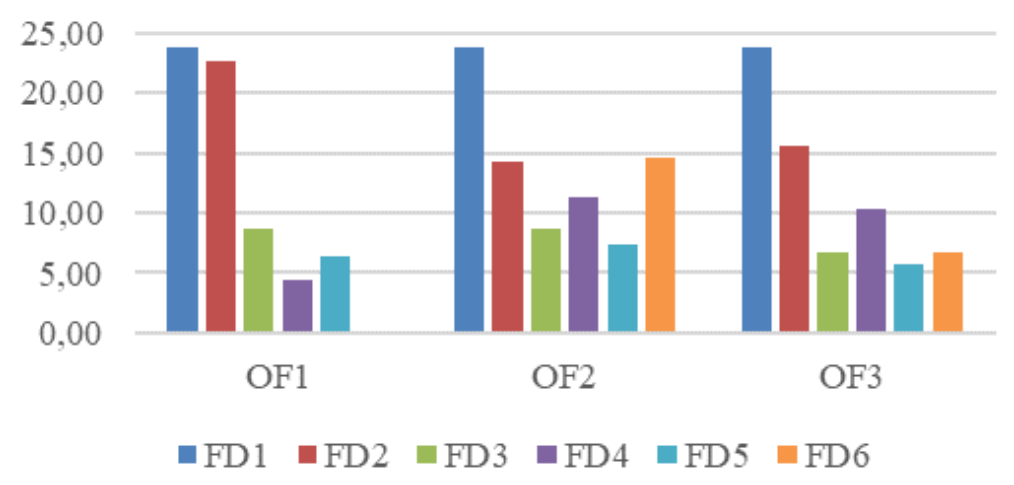

Figure 14. The interaction of organic fertilizers' germinated seed number

\section{The relationships among the observed characteristics}

In the study, a correlation analysis was conducted to reveal the relationships between all investigated properties of Brassica napus L. seeds subjected to organic fertilizer forms and doses. The many of correlations between all the examined properties are considered to be significant $(\mathrm{P}<0.01$ and $\mathrm{P}<0.05)$ with different organic fertilizer form doses (Table 3). As presented in Table 3, one of the most important features is the germination percentage. It was found to have significant positive correlations with GI, RL, PL, SL, PFW, SFW, PDW, SDW, SVI, and GSN ( $r=0.942, r=0.764, r=0.701, r=0.765, r=0.359$, $\mathrm{r}=0.315, \mathrm{r}=0.358, \mathrm{r}=0.315, \mathrm{r}=0.916$, and $\mathrm{r}=1.000$, respectively). Table 3 can be examined for the positive and negative relationship among other characteristics.

Table 3. Correlation table for observed parameters of Brassica napus L. samples for fertizer forms and fertilizer doses

\begin{tabular}{|c|c|c|c|c|c|c|c|c|c|c|c|c|}
\hline & GI & RL & PL & SL & RFW & PFW & SFW & RDW & PDW & SDW & SVI & GSN \\
\hline GP & 0.942 ** & 0.764 & ${ }^{*} 0.701 *$ & $0.765^{* * *}$ & 0.030 & $0.359^{* *}$ & 0.315 & 0.031 & 0.358 * & $0.315^{*}$ & 0.916 & ${ }^{*} 1.000$ * \\
\hline GI & & $0.757^{* *}$ & ${ }^{*} 0.6377^{* *}$ & $0.742^{* *}$ & 0.116 & $0.409^{* *}$ & $0.376^{* *}$ & 0.116 & 0.409 * & * 0.376 & " 0.942 * & " 0.942 * \\
\hline RL & & & $0.883^{* *}$ & $0.991 * *$ & 0.046 & $0.294^{*}$ & 0.262 & 0.047 & $0.294^{*}$ & 0.262 & $0.914^{* *}$ & " 0.764 ** \\
\hline PL & & & & $0.937^{* *}$ & -0.116 & 0.169 & 0.121 & -0.115 & 0.169 & 0.121 & $0.802 *$ & " 0.701 * \\
\hline SL & & & & & 0.002 & 0.266 & 0.229 & 0.002 & 0.266 & 0.229 & 0.904 * & * $0.765^{*}$ \\
\hline RFW & & & & & & $0.597^{* *}$ & * $0.724^{* * *}$ & " 0.999 * & 0.597 & * 0.724 & * 0.027 & 0.030 \\
\hline PFW & & & & & & & $0.986^{* *}$ & * 0.597 * & * 1.000 ** & * 0.986 * & * 0.338 * & 0.359 \\
\hline SFW & & & & & & & & 0.724 & 0.986 & ** 1.000 ** & * 0.296 * & 0.315 \\
\hline RDY & & & & & & & & & 0.597 * & * 0.724 ** & * 0.027 & 0.031 \\
\hline PDW & & & & & & & & & & 0.986 ** & * 0.338 * & 0.358 \\
\hline SDW & & & & & & & & & & & $0.296^{*}$ & $0.315^{*}$ \\
\hline SVI & & & & & & & & & & & & $0.916^{*}$ \\
\hline
\end{tabular}

\section{Conclusion}

According to the results of the research, it was observed that organic fertilizer forms significantly affect the parameters of rapeseed germination and seedling growth. 
The findings of the study showed that fertilizer $\mathrm{x}$ dose interactions were beneficial in determining the inhibitory properties of rapeseed seeds as well as in promoting germination and seedling growth. Although germination percentage, germination index, radicle length, plumule length, seedling length and plumula fresh weight values are highest in control doses; radicle fresh weight, plumule fresh weight, seedling fresh weight, radicle dry weight, plumule dry weight and seedling dry weight values were found to be highest, especially in $2000 \mathrm{ppm} \mathrm{L}^{-1}$ doses.

As a summary, while the liquid seaweed $2000 \mathrm{ppm} \mathrm{L}^{-1}$ dose application, plumule fresh weight, seedling fresh weight, radicle dry weight and seedling dry weight were highest, plumule fresh weight seedling fresh weight, plumule dry weight and seedling dry weight values proved to be second high values in $4000 \mathrm{ppm} \mathrm{L}^{-1}$ dosing application. The liquid vermicompost had an effect of increasing seedling length by promoting both root and shoot length of rapeseed. The liquid seaweed had a negative effect on both root and shoot length of rapeseed, while promoting seedling growth, and had an effect increase seedling fresh weight. The form of liquid organic fertilizer with plant-derived amino acids had a stimulating effect on the germination rate of rapeseed.

There was no germination at the highest applied dose $\left(16000 \mathrm{ppm} \mathrm{L}^{-1}\right)$ of the liquid seaweed. In fertilizer doses; in $16000 \mathrm{ppm} \mathrm{L}^{-1}$ application, it was determined that it gave the lowest values in germination index, radicle length, radicle fresh weight, plumule fresh weight, seedling fresh weight, radicle dry weight, plumule dry weight and seedling dry weight, and the application of $16000 \mathrm{ppm} \mathrm{L}^{-1}$ fertilizer dose had a negative effect on the germination and seedling growth of rapeseed in organic fertilizer forms investigated.

According to the data obtained in the study, it was observed that the fertilizers of organic origin applied did not have a positive effect on the germination rate and index, but after the germination, it was observed that the seaweed manure had positive and significant effects on seedling growth, while the worm manure had the same effect on the seedling lengths.

In future studies, it is necessary to diversify the studies on organic fertilizers, especially liquid seaweed, which promotes seedling growth, and liquid worm manure, which promotes seedling length. In order to emphasize the importance of these fertilizer forms, it will be important to carry out more studies in different plants, as well as to use other organic fertilizers in these studies to be conducted, to obtain healthier and more accurate data.

\section{REFERENCES}

[1] Alam, M. N., Jahan, M. S., Ali, M. K., Islam, M. S., Khandaker, S. M. A. T. (2007): Effect of vermicompost and NPKS fertilizers on growth, yield and yield components of Red Amaranth. - Australian Journal of Basic and Applied Sciences 1(4): 706-716.

[2] Algan, N. (1990): Feeding rapeseed cultivation and development opportunities in Turkey. - The Voice of Agriculture Journal 165(20): 1-3.

[3] Amanpoor, B., Sedghi, B., Salamat, B., Bakhshi, J. (2011): The effect of priming with Marmarin on the features of germination of bean seeds under salinity. - The $2^{\text {nd }}$ national conference on Seed Science and Technology. Islamic Azad University, Mashhad branch, pp. 660-664.

[4] Aygün, Y., Acar, M. (2004): Organic fertilizers and their importance. - Journal of Harvest 228: 68-72. 
[5] Benitez, E., Nogales, R., Masciandaro, G., Ceccanti, B. (2000): Isolation by isoelectric focusing of humic-urease complexes from earthworm (Eisenia fetida)-processed sewage sludges. - Biology And Fertility of Soils 31(6): 489-493.

[6] Demir, N., Dural, B., Yıldırım, Y. (2006): Effect of seaweed suspension on seed germination of tomato, pepper and aubergine. - Journal of biological science 6(6): 11301133.

[7] Demirkaya, M. (2010): Effects of seaweed (Ascophyllum nodosum) extract application on viability and vigour of pepper and onion seeds. - Erciyes University Journal of the Institute of Science and Technology 26(3): 217-224.

[8] Demirkaya, M. (2012): The effects of seaweed (Ascophyllum nodosum) extract treatments on viability and vigor of tomato seeds. - Journal of Alatarım of Erciyes University 11(1): 13-18.

[9] FAOSTAT. (2020): FAO Statistics Database (The Production, Production Area and Yield of Rapeseed). - http://www.faostat.fao.org/ (Date of access: 20.04.2020).

[10] Kacar, B. (2013): Basic fertilizer information. - Nobel Akademik Publications, Ankara, $503 \mathrm{pp}$.

[11] Ma, Z., Bykova, N. V., Igamberdiev, U. A. (2017): Cell signaling mechanisms and metabolic regulation of germination and dormancy in barley seeds. - The Crop Journal 5(6): 459-477.

[12] Masondo, N. A., Kulkarni, M. G., Finnie, J. F., Van Staden, J. (2018): Influence of biostimulants-seed-priming on Ceratotheca triloba germination and seedling growth under low temperatures, low osmotic potential and salinity stress. - Eco-toxicology and environmental safety 147: 43-48.

[13] Matysiak, K., Kaczmarek, S., Krawczyk, R. (2011): Influence of seaweed extracts and mixture of humic and fulvic acids on germination and growth of Zea mays L. - Acta Sci. Pol. 10(1): 33-45.

[14] Sharma, H. S., Fleming, C., Selby, C., Rao, J. R., Martin, T. (2014): Plant biostimulants: a review on the processing of macroalgae and use of extracts for crop management to reduce abiotic and biotic stresses. - Journal of Applied Phycology 26(1): 465-490.

[15] Spinelli, F., Giovanni, F., Massimo, N., Mattia, S., Guglielmo, C. (2010): A novel type of seaweed extract as a natural alternative to the use of iron chelates in strawberry production. - Scientia Horticulturae 125: 263-269.

[16] Steel, R. G. D., Torrie, J. H. (1980): Principles and procedures of statistics. - McGrawHill, New York.

[17] Şeker, A. (2015): Determination of abiotic disorders and the identification of Beet western yellows virus (BWYV) and Turnip mosaic virus (TuMV)'es by Das-Elisa in canola (Brassica napus L.) fields of the Trakya region in Turkey. - M.Sc. Thesis. Namık Kemal University, Graduate School of Natural and Applied Science, Department of Plant Protection. Tekirdağ. 8-9.

[18] Tosun, A., Özkal, N. (2000): Canola. - Journal of Faculty of Pharmacy of Ankara University 29(1): 59-76.

[19] TURKSTAT. (2020): Turkish Statistical Institute (The Production, Production Area and Yield of Rapeseed). - http://www.tuik.gov.tr/ (Date of access: 26.02.2020).

[20] Yıldırım, E., Güvenç, İ. (2005): The effect of seaweed extract treatments on germination of leek seeds under salinity. - Journal of Garden 34(2): 83-87.

[21] Yıldırım, E. (2019): Extension of the shelf life of liquid wormgrass. - M.Sc. Thesis. Karabük University, Graduate School of Natural and Applied Science, Department of Chemistry. Karabük. 2-3.

[22] Y1lmaz, S. (2015): Determination of the effects of gibberellic acid on GABA and antioxidant defence system in Phaseolus vulgaris L. (bean) plants exposed to salt and drought stresses. - M.Sc. Thesis. Aksaray University, Graduate School of Natural and Applied Science, Department of Biology. Aksaray. 13 pp. 
[23] Yüksek, T., Atamov, V., Türüt, K. (2019): Determination of some nutrient elements in solid vermicompost obtained from red california worm feeding with brewed tea waste and domestic food waste. - Journal of Anatolian Environmental and Animal Sciences 4(2): 263-271. 